\title{
Identification of genes regulating traits targeted for domestication of field cress (Lepidium campestre) as a biennial and perennial oilseed crop
}

\author{
Cecilia Gustafsson', Jakob Willforss², Fernando Lopes-Pinto ${ }^{3}$, Rodomiro Ortiz ${ }^{1}$ and Mulatu Geleta ${ }^{1 *}$ (D)
}

\begin{abstract}
Background: The changing climate and the desire to use renewable oil sources necessitate the development of new oilseed crops. Field cress (Lepidium campestre) is a species in the Brassicaceae family that has been targeted for domestication not only as an oilseed crop that produces seeds with a desirable industrial oil quality but also as a cover/catch crop that provides valuable ecosystem services. Lepidium is closely related to Arabidopsis and display significant proportions of syntenic regions in their genomes. Arabidopsis genes are among the most characterized genes in the plant kingdom and, hence, comparative genomics of Lepidium-Arabidopsis would facilitate the identification of Lepidium candidate genes regulating various desirable traits.
\end{abstract}

Results: Homologues of 30 genes known to regulate vernalization, flowering time, pod shattering, oil content and quality in Arabidopsis were identified and partially characterized in Lepidium. Alignments of sequences representing field cress and two of its closely related perennial relatives: L. heterophyllum and L. hirtum revealed 243 polymorphic sites across the partial sequences of the 30 genes, of which 95 were within the predicted coding regions and 40 led to a change in amino acids of the target proteins. Within field cress, 34 polymorphic sites including nine nonsynonymous substitutions were identified. The phylogenetic analysis of the data revealed that field cress is more closely related to L. heterophyllum than to L. hirtum.

Conclusions: There is significant variation within and among Lepidium species within partial sequences of the 30 genes known to regulate traits targeted in the present study. The variation within these genes are potentially useful to speed-up the process of domesticating field cress as future oil crop. The phylogenetic relationship between the Lepidium species revealed in this study does not only shed some light on Lepidium genome evolution but also provides important information to develop efficient schemes for interspecific hybridization between different Lepidium species as part of the domestication efforts.

Keywords: Domestication, Field cress, Lepidium campestre, Pod shattering, Vernalization

\section{Background}

Domestication is the process of selecting genetic polymorphisms for traits that suit human needs. The "domestication syndrome" describes the main differences between domesticated and wild plants. Traits that normally are associated with the domestication syndrome

\footnotetext{
* Correspondence: Mulatu.Geleta.Dida@slu.se

${ }^{1}$ Department of Plant Breeding, Swedish University of Agricultural Sciences, Box 101, SE-23053 Alnarp, Sweden

Full list of author information is available at the end of the article
}

include reduced seed dormancy, seed dispersal resistance, free threshing and high number of seeds per plant [1]. Historically, domestication of plants has been a slow and a labor-intense task as breeders have relied only on phenotypes to improve the crop. Although this approach has been very successful, it has its own drawbacks. It is time consuming, costly and can be influenced by the environment. The recent rapid development of genomics can make it possible to domesticate a new plant with less labor and within a significantly shorter time frame.

(c) The Author(s). 2018 Open Access This article is distributed under the terms of the Creative Commons Attribution 4.0 International License (http://creativecommons.org/licenses/by/4.0/), which permits unrestricted use, distribution, and reproduction in any medium, provided you give appropriate credit to the original author(s) and the source, provide a link to the Creative Commons license, and indicate if changes were made. The Creative Commons Public Domain Dedication waiver (http://creativecommons.org/publicdomain/zero/1.0/) applies to the data made available in this article, unless otherwise stated. 
The use of genomic tools and resources can speed up a domestication process as breeders can select plants bearing desirable traits before the traits have been expressed, using appropriate DNA markers and high-throughput precise phenotyping.

While farming systems with annual crops have provided us with unprecedented yield, they have also contributed to ecosystem problems such as soil erosion and water runoff [2]. Perennial crops normally have deeper root systems that can prevent soil erosion, reduce water runoff and nutrient leakage. In addition, perennial crops may require less herbicide treatment as its extended growing season enables it to outcompete weeds. The few examples of successful breeding programs of perennial crops include perennial rice and intermediate wheatgrass $[3,4]$. There are also currently interesting attempts to develop perennial oil crops such as sunflower [5].

To meet the growing demand for a renewable oil production and reduce the negative effects of annual crop systems, we are in the process of domesticating a new seed oil crop: field cress (Lepidium campestre (L.) R. Br., also called pepperworth), which is a wild species in the Brassicaceae family. It has many good agronomic characteristics, which makes it a promising candidate for domestication. It has a relatively small diploid genome with a sporophytic chromosome number of $2 \mathrm{n}=16$ [6]. Field cress is a self-fertilized biennial plant with closely related perennials (L. hirtum (L.) Sm. and L. heterophyllum Benth.), which can be used as a source of perenniality genes for the development of perennial field cress [7]. Although polyploids are common among Lepidium species, both L. heterophyllum and $L$. hirtum are diploids with $2 \mathrm{n}=16$ chromosomes and can be cross-hybridized with field cress to produce viable hybrid plants [8]. Moreover, field cress is extremely winter hardy, resistant to the pollen beetle, have a high seed yield (>4500 $\mathrm{kg} \mathrm{ha}^{-1}$ ) and a good seed size (half the size of that of large seeded rapeseed) [9, 10]. Field cress produces a high-quality seed oil suitable for industrial use, with linolenic and erucic acids being the main components.

Field cress has been targeted for domestication as an under sown cover-, catch- and oilseed crop to prevent nutrient leaching as well as being a high yielding crop [10]. It can be under sown with a spring cereal and serve as a cover and catch crop, after the harvest of the cereal in the summer, and finally harvested as an oil crop the second year. Hence, field cress holds high agronomic potential and eco-friendliness as it could simultaneously function as a high yielding oil crop and a cover/catch crop. Unlike rapeseed, which is not widely cultivated in areas with strong winter due to its poor winter-hardiness, field cress has been proven to be productive in a colder climate. Thus, cultivation of field cress could be of great value to farmers in the northern parts of temperate regions, e.g. Nordic Europe. Both crossbreeding and genetic engineering based approaches are being used for domestication of field cress. In line with this, floral dip based-, and tissue culture based transformation protocol have been successfully established for field cress [11, 12]. However, as the use of genetically modified plants is still very restricted within Europe, crossbreeding techniques are still essential.

As the cost for sequencing technology has been greatly reduced, comparative genomics has become an increasingly important tool in agriculture. Arabidopsis thaliana (thale cress) is among the most investigated plants in the plant kingdom and since the publication of the genome in the year 2000 [13], a vast number of genes have been identified and characterized. The publication of 1135 additional A. thaliana genomes provided information about the global pattern of polymorphisms [14]. Seed dispersal resistance, flowering time, winter hardiness, perenniality, oil content and oil quality are among the major traits targeted for field cress breeding at early stages of the domestication process. A number of genes regulating these traits are well known in Arabidopsis and Brassica, which are in the same Brassicaceae family as field cress. The close evolutionary relationship between Arabidopsis and field cress makes Arabidopsis an ideal species to identify orthologs of these genes in field cress through comparative genomics. Analyses of genes that are associated with vernalization and flowering time is important in order to facilitate the development of a winter hardy perennial field cress. MADS-box genes such as FLOWERING LOCUS C (FLC) play a key role in regulating plant developmental responses to temperature $[15,16]$. The gene FRIGIDA (FRI) enhances the expression of $F L C$ and has been demonstrated to be of great importance for vernalization and flowering time $[17,18]$.

VERNALIZATION INSENSITIVE 3 (VIN3) is part of the polycomb repression complex PRC2 which establishes repression of $F L C$ and is one of the earliest responses to vernalization $[19,20]$. Downregulation of FLC promotes floral development and the low levels of $F L C$ are maintained after the cold treatment by $R E$ DUCED VERNALIZATION RESPONSE 1 and 2 (VRN1 and VRN2) which serves as a molecular memory of the vernalization [20, 21]. SUPRESSOR OF OVEREXPRESSION OF CO1 (SOC1, also AGAMOUS LIKE 20/AGL20) and FRUITFULL (FUL) are controlling flowering as well as determinacy of meristems but also seem to be involved in inhibiting longevity in annual plants [22-24]. FLC, FRI, VIN3, VRN1 and VRN2 were among main targets in the present study as their role in vernalization and flowering time has been well established. SOC1 and $F U L$ were also interesting for their reported effect on perenniality. Analysis of field cress orthologs of $A G A$ MOUS LIKE 6 (AGL6), AGAMOUS LIKE 16 (AGL16) and MADS AFFECTING FLOWERING 2-5 (MAF2-5) 
which are reported to have effect on these traits [25-28] are also of interest.

Shattering of pods (fruit dehiscence) can lead to significant yield losses and pod shattering resistance is therefore a highly advantageous trait in any domesticated crop. Hence, identification and analysis of transcription factor genes, FUL and REPLUMLESS (RPL), together with the valve identity genes INDEHISCENT (IND), ALCATRAZ (ALC), SHATTERPROOF 1 and 2 (SHP1 and SHP2) that are responsible for the establishment of the valve margin in the seed-containing pod, and regulate thereby the release of seeds from the pod, [29-34] should be targeted as important steps towards the development of shatter proof field cress cultivars. In addition, genes encoding ARABIDOPSIS DEHISCENCE ZONE POLYGALACTURONASE 1 and 2 (ADPG1 and ADPG2) and the NAC DOMAIN CONTAINING PROTEIN 12 (NAC012/SND1) which are contributing to fruit dehiscence $[35,36]$ are also important targets.

Because field cress is targeted as an oilseed crop, genes that code for both oil content and quality need to be analyzed as integral part of the domestication process so that acceptable levels of oil content and quality can be achieved. Among the various genes involved in the biosynthesis of fatty acid ACYL-COA:DIACYLGLYCEROL ACYLTRANSFERASE 1 (TAG1) and WRINKLED 1 (WRI1) regulate oil production in many species, including Arabidopsis and FATTY ACID DESATURASE 2 (FAD2), FATTY ACID ELONGATION 1 (FAE1) and 3-KETOACYL-COA-SYNTHASE 8 (KCS8) are controlling seed oil composition in most oil crops [37-42]. Other important traits in field cress include host plant resistance to pathogens and seed dormancy. Hence, genes involved in regulating these traits are important targets. Homologous sequences in field cress for host plant resistance gene FERONIA (FER) and plant defense gene AUTOPHAGY RELATED 5 (ATG5), genes that are involved in germination of seeds AGAMOUS-LIKE 11 (AGL11) and HIGHLY ABA-INDUCED PP2C PROTEIN 2 (HAI2/AIP1) [43-46] were also in focus.

The present study aimed at the identification of the orthologues of the aforementioned genes in field cress through comparative analysis of its genome with that of Arabidopsis and Brassica; characterization of the genetic diversity of these genes in field cress; and analyzing the effect of different mutations in each gene on the plant phenotypes in field cress and related species.

\section{Methods}

\section{Plant material}

A total of 31 individual plants of field cress, L. hirtum, $L$. heterophyllum and interspecific hybrids of field cress and L. heterophyllum (CHe hybrids) was used for this study (Table 1). Ten field cress and two $\mathrm{F}_{3} \mathrm{CHe}$ hybrids were among 18 Lepidium samples used for sequencing the restriction site associated DNA (RAD) [46]. The remaining 19 individuals -comprising 14 field cress, three L. hirtum and two L. heterophyllum- (Table 1) were used for the sequencing of partial sequences of target genes after they were identified based on comparative genomic analysis of Lepidium RAD-sequences and genomic sequences of Arabidopsis and Brassica. These Lepidium accessions were obtained from various genebanks and botanical gardens in Europe as well as after collecting populations from various regions in Sweden. Except the CHe hybrids, the samples were selfed at least for four generations in a greenhouse. The $\mathrm{CHe}$ hybrids are the result of interspecific hybridization followed by two rounds of selfing. These samples were chosen for their geographical spread and their phenotypic variation.

\section{Comparative genomics/bioinformatics and primer design}

The RAD-sequencing conducted on 18 Lepidium samples comprising 10 field cress, two $\mathrm{F}_{3} \mathrm{CHe}$ hybrids and three progenies of each of the two $\mathrm{CHe}$ hybrids at Edinburgh Genomics (School of Biological Sciences, University of Edinburgh, EH9 3FL, Edinburgh, UK) produced over 190,000 consensus RAD-sequences [47]. A BLAST search for sequences that match the RAD sequences in the National Center for Biotechnology Information (NCBI) database identified sequences that have 75 to $90 \%$ sequence identity with the Arabidopsis genome sequences, with e-values ranging from 0.0 to $1 \mathrm{e}^{-11}$. Additional top hits included sequences of other Brassicaceae species such as Brassica rapa, Camelina sativa and Boechera stricta. All DNA sequences used for comparative genomic analysis except those of Lepidium were retrieved from the NCBI database.

DNA sequences of 30 genes (see Table 2) from A. thaliana and field cress known to be regulators of desirable traits for plant domestication were used as query sequences to find any homologous sequences in the RAD sequence pool. However, since the RAD-sequences were short sequences (117 nucleotides (nt) to $567 \mathrm{nt}$ long), they only represent short segments of these genes. In total, DNA sequences homologous to partial sequences of 24 different genes were identified through using this approach (Additional file 1: Table S1). Primers were then designed using field cress RAD-sequences as a template by mainly targeting coding regions in 18 of these 24 genes. Although sequences homologous to partial sequences of the remaining six genes (AGL11, ALC, FUL, HAI2, IND, and SOC1) were found among the RAD-sequences, conserved Arabidopsis sequences were used to design primers in order to expand the regions to be sequenced. Six of the 30 genes (ADPG1, AP2, FAE1, FLC, NAC012 and RPL) did not show any homology to the RAD sequences, and hence conserved sequences in $A$. thaliana or previously 
Table 1 Sample codes, source and country of origin of different genotypes of three Lepidium species and CHe hybrids analyzed for genetic variation within partial sequences of various genes regulating desirable traits. L. hirtum is represented by three subspecies. Genotypes 1-14 and 27-31 were amplified and sequenced using newly designed primers (Additional file 1: Table S1) while genotypes 15-26 were those used in the RAD-Sequencing project

\begin{tabular}{|c|c|c|c|c|c|}
\hline \multirow[t]{2}{*}{ No } & \multirow[t]{2}{*}{ Sample code } & \multirow[t]{2}{*}{ Species } & \multicolumn{2}{|c|}{ Source accession/population } & \multirow[t]{2}{*}{ Country of origin } \\
\hline & & & name & obtained from & \\
\hline 1 & LCSma & L. campestre & Mörbylånga & Newly collected & Öland, Sweden \\
\hline 2 & LeSstu & L. campestre & Stuvsta & Newly collected & Södermanland, Sweden \\
\hline 3 & LcCze & L. campestre & PI 633248 & USDA-ARS & Czechoslovakia \\
\hline 4 & LcGer1 & L. campestre & LEP 122 & IPK, Germany & Germany \\
\hline 5 & LcSho & L. campestre & Höör2 & Newly collected & Skåne, Sweden \\
\hline 6 & LcGer2 & L. campestre & LEP 93 & IPK, Germany & Germany \\
\hline 7 & LCSlj & L. campestre & Ljugarn & Newly collected & Gotland, Sweden \\
\hline 8 & LcGer3 & L. campestre & PI 633251 & USDA-ARS & Germany \\
\hline 9 & LCSkr & L. campestre & Kristianstad & Newly collected & Skåne, Sweden \\
\hline 10 & LcSar & L. campestre & Årsta1 & Newly collected & Södermanland, Sweden \\
\hline 11 & LCSvi & L. campestre & Viken & Newly collected & Skåne, Sweden \\
\hline 12 & LcSsk & L. campestre & Skövde & Newly collected & Västergötland, Sweden \\
\hline 13 & LcSsp & L. campestre & Spjutstorp & Newly collected & Skåne, Sweden \\
\hline 14 & LcSve & L. campestre & Ventlinge & Newly collected & Öland, Sweden \\
\hline 15 & LcFra & L. campestre & PI 633252 & USDA-ARS & France \\
\hline 16 & LcGre1 & L. campestre & LEP 89 & IPK, Germany & Greece \\
\hline 17 & LCSst & L. campestre & 094-10 & Newly collected & Stjärnelund, Sweden \\
\hline 18 & LCUK & L. campestre & 0018580 & Royal Botanic Garden, UK & $?$ \\
\hline 19 & LcSga & L. campestre & Gävle & Newly collected & Gävleborg, Sweden \\
\hline 20 & LcStr & L. campestre & Trelleborg & Newly collected & Skåne, Sweden \\
\hline 21 & LcGer4 & L. campestre & LEP 94 & IPK, Germany & Germany \\
\hline 22 & LcGre2 & L. campestre & LEP 92 & IPK, Germany & Greece \\
\hline 23 & LcDen 1 & L. campestre & 49324 & Botanic Garden-Denmark & $?$ \\
\hline 24 & LcDen2 & L. campestre & NGB22634 & NordGen, Sweden & Denmark \\
\hline 25 & $\mathrm{CH} 1^{\mathrm{a}}$ & L. campestre $x$ heterophyllum ${ }^{a}$ & LEP $89 \& 597856$ & IPK, Germany \& USDA-ARS & Germany \& Spain \\
\hline 26 & $\mathrm{CH} 2^{\mathrm{a}}$ & L. campestre $x$ heterophyllum ${ }^{a}$ & Huddinge \& 597856 & Newly collected \& USDA-ARS & Sweden \& Spain \\
\hline 27 & LheGer & L. heterophyllum & 1988/690-148 & Marburg Bot. garden, Germany & $?$ \\
\hline 28 & LheSha & L. heterophyllum & Hästveda & Newly collected & Skåne, Sweden \\
\hline 29 & Lhilta & L. hirtum ssp. nebrodense & PI633253 & USDA-ARS & Italy \\
\hline 30 & LhiSpa & L. hirtum ssp. calycotrichum & PI597858 & USDA-ARS & Spain \\
\hline 31 & LhiMor & L. hirtum ssp. atlanticum & Ames 21387 & USDA-ARS & Morocco \\
\hline
\end{tabular}

ahybrid of L. campestre and L. heterophyllum;? = no information

published field cress mRNA sequences were used as a template to design primers for amplification of orthologous regions in field cress.

\section{DNA extraction}

Genomic DNA was obtained by sampling leaf tissue from young plants, grown in a green house, which was flash-frozen in liquid nitrogen and homogenized by vigorously shaking in a Retsch MM400. The samples were incubated with $1 \mathrm{ml}$ of pre-warmed CTAB buffer
(0.1 M Tris, $20 \mathrm{mM}$ EDTA, 1.4 M NaCl, 2\% CTAB, $\mathrm{pH} 7.5$ ) for $1 \mathrm{~h}$ at $52{ }^{\circ} \mathrm{C}$. The samples were then centrifuged for $15 \mathrm{~min}$ at $14.1 \mathrm{rpm}$ in an Eppendorf miniSpin tabletop centrifuge. The supernatant was then transferred to sample plate and DNA was extracted using the Qiacube DNA extraction robotic workstation (Qiagen). The extracted DNA was finally ran on a $1 \%$ agarose gel and checked for impurities on a Nanodrop. DNA from the 19 individuals (Table 1) was used for screening partial sequences of the 30 target genes (Table 3). 
Table 2 Sequence identity (\%) between field cress and seven other Brassicaceae species within partial sequences of coding regions of 30 genes regulating desirable traits in crops

\begin{tabular}{|c|c|c|c|c|c|c|c|c|c|}
\hline Gene & Trait/gene function & A.lyrata & A. thaliana & Brapa & B.napus & B.oleracea & Camelina sativa & Capsella rubella & Mean \\
\hline AGL11 & SD & 95 & 95 & 91 & 92 & 92 & 96 & 96 & 93.9 \\
\hline SOC1 & FT & 94 & 94 & 93 & 93 & 93 & 94 & 93 & 93.4 \\
\hline TAG1 & OC & 94 & 93 & 93 & 93 & 93 & 93 & 95 & 93.4 \\
\hline AGL6 & FT & 95 & 98 & 90 & 91 & 91 & 92 & 92 & 92.7 \\
\hline VRN1 & VRN & 94 & 94 & 90 & 90 & 90 & 92 & 94 & 92.0 \\
\hline NAC012 & PSH & 92 & 92 & 91 & 91 & 90 & 93 & 92 & 91.6 \\
\hline FER & $\mathrm{DR}$ & 93 & 93 & 89 & 89 & 89 & 92 & 91 & 90.9 \\
\hline FUL & $\mathrm{FT}, \mathrm{PSH}$ & 92 & 92 & 89 & 89 & 89 & 90 & 90 & 90.1 \\
\hline$F L C$ & $\mathrm{FT}, \mathrm{VRN}$ & 89 & 90 & 88 & 88 & 88 & 90 & 92 & 89.3 \\
\hline MAF2 & VRN & 93 & 95 & 87 & 84 & 85 & 91 & 89 & 89.1 \\
\hline MAF5 & VRN & 93 & 95 & 87 & 84 & 85 & 91 & 89 & 89.1 \\
\hline$A P 2$ & FT & 89 & 89 & 89 & 89 & 89 & 90 & 88 & 89.0 \\
\hline$A D P G 1$ & PSH & 89 & 91 & 88 & 86 & 87 & 91 & 90 & 88.9 \\
\hline SHP1 & PSH & 90 & 90 & 89 & 89 & 89 & 89 & 86 & 88.9 \\
\hline SHP2 & PSH & 91 & 89 & 86 & 87 & 87 & 89 & 92 & 88.7 \\
\hline FAD2 & $\mathrm{OQ}$ & 91 & 91 & 85 & 85 & 85 & 90 & 91 & 88.3 \\
\hline VRN2 & VRN & 92 & 90 & 83 & 84 & 84 & 89 & 88 & 87.1 \\
\hline GTR2 & GTR & 88 & 88 & 86 & 86 & 86 & 88 & 88 & 87.1 \\
\hline FAE1 & $\mathrm{OQ}$ & 89 & 88 & 85 & 85 & 85 & 89 & 88 & 87.0 \\
\hline$R P L$ & $F T, P S H$ & 89 & 89 & 85 & 85 & 84 & 88 & 88 & 86.9 \\
\hline VIN3 & VRN & 87 & 86 & 85 & 85 & 84 & 85 & 85 & 85.3 \\
\hline WRI1 & OC & 88 & 88 & 82 & 82 & 83 & 86 & 87 & 85.1 \\
\hline KCS8 & $\mathrm{OQ}$ & 88 & 87 & 82 & 83 & 82 & 87 & 86 & 85.0 \\
\hline ADPG2 & PSH & 85 & 84 & 82 & 82 & 82 & 89 & 90 & 84.9 \\
\hline IND & PSH & 86 & 85 & 84 & 86 & 76 & 85 & 84 & 83.7 \\
\hline$A L C$ & PSH & 82 & 83 & 81 & 81 & 81 & 82 & 84 & 82.0 \\
\hline AGL16 & FT & 82 & 84 & 81 & 81 & 82 & 82 & 81 & 81.9 \\
\hline$F R I$ & VRN, FT & 84 & 81 & 81 & 81 & 80 & 82 & 83 & 81.7 \\
\hline HAI2 & SD & 82 & 82 & 81 & 80 & 80 & 81 & 82 & 81.1 \\
\hline ATG5 & PD & 82 & 81 & 79 & 80 & 72 & 84 & 80 & 79.7 \\
\hline Mean & & 89.3 & 89.2 & 86.1 & 86.0 & 85.4 & 88.7 & 88.5 & 87.6 \\
\hline
\end{tabular}

DR Disease resistance, FT Flowering time, OC Oil content, OQ Oil quality, PD Plant defense, PSH Pod shattering, SD Seed dormancy, GTR Glucosinolate Transport, $V R N$ Vernalization. Note: The matching of the Lepidium sequences with the right Arabidopsis gene sequences is highly significant, with e-values ranging from 0.0 to $1 \mathrm{e}^{-11}$

\section{PCR and DNA sequencing}

PCR mix for a $25 \mu$ reaction volume contained $1 \times$ PCR buffer, $1.5 \mathrm{mM} \mathrm{MgCl}_{2}, 0.3 \mathrm{mM}$ dNTPs, $0.2 \mu \mathrm{M}$ of each primer, $1 \mathrm{U}$ Dream Taq polymerase (ThermoFisher Scientific) and $1 \mathrm{ng} / \mu \mathrm{l}$ DNA template. The conditions of PCR cycling were: $95{ }^{\circ} \mathrm{C}$ for $5 \mathrm{~min}$; 35-40 cycles of $95{ }^{\circ} \mathrm{C}$ for $15 \mathrm{~s}, 52$ to $60{ }^{\circ} \mathrm{C}$, (depending on the primer-pair) for $15 \mathrm{~s}$, and $72{ }^{\circ} \mathrm{C}$ for $40 \mathrm{~s}$; and a final step of $72{ }^{\circ} \mathrm{C}$ for $10 \mathrm{~min}$. PCR product clean-up and sequencing was performed at MWG Eurofins Genomics, Germany. DNA sequence data generated in this study have been deposited at the NCBI/
GenBank and the accession numbers of the sequences are given in Additional file 2: Table S2.

\section{Sequence analyses}

The diversity analyses are based on the 12 individuals (10 field cress and two $\mathrm{CHe}$ hybrids) from the RAD-sequencing and the 19 individuals (14 field cress, three L. hirtum, two L. heterophyllum) from the resequencing work. From the RAD-sequencing data, variants corresponding to each individual were generated using GATK's HaplotypeCaller command (GATK version 3.5; a toolkit 
Table 3 Variation (SNPS and indels) found in aligned sequences of L. campestre, L. heterophyllum and L. hirtum as well as in aligned sequences of different $L$. campestre genotypes. The analyzed sequence length, number of polymorphism (Polym), number of nonsynonymous mutations (Non-syn), the number of species specific polymorphisms (Species spec. polym) and percent polymorphism per nucleotide (Polym/nt) are listed according to gene

\begin{tabular}{|c|c|c|c|c|c|c|c|c|c|}
\hline \multirow[t]{2}{*}{ Gene } & \multirow[t]{2}{*}{ Trait/gene function } & \multirow{2}{*}{$\begin{array}{l}\text { Analyzed } \\
\text { sequence } \\
\text { length }^{a}\end{array}$} & \multicolumn{4}{|c|}{ L. campestre + L. hirtum $+L$ heterophyllum } & \multicolumn{3}{|c|}{ L. campestre only } \\
\hline & & & Polym $^{a}$ & Non-syn ${ }^{b}$ & $\begin{array}{l}\text { Polym } / \mathrm{nt}^{\mathrm{a}} \\
\text { (\%) }\end{array}$ & Species spec. polym ${ }^{\mathrm{a} c}$ & Polym $^{a}$ & Non-syn ${ }^{b}$ & $\begin{array}{l}\text { Polym } / \mathrm{nt}^{2} \\
(\%)\end{array}$ \\
\hline$\overline{F R I}$ & vernalization, flowering time & $606 \_498$ & $13 \_8$ & 6 & 2.1_1.6 & 0_0 (0) & $3 \_3$ & 2 & $0.5 \_0.6$ \\
\hline MAF2 & vernalization & 532_181 & 7_3 & 2 & 1.3_1.7 & 0_0 (0) & 7_3 & 2 & 1.3_1.7 \\
\hline MAF5 & vernalization & 365_206 & 4_4 & $1^{d}$ & $1.1 \_1.9$ & $0 \_1(0)$ & $1 \_1$ & 0 & $0.3 \_0.5$ \\
\hline VIN3 & vernalization & 1347_1121 & 7_5 & 4 & $0.5 \_0.4$ & $0 \_1(1)$ & $0 \_0$ & 0 & 0_0 \\
\hline VRN1 & vernalization & 1545_501 & $2 \_1$ & 1 & $0.1 \_0.2$ & 0_0 (0) & $2 \_1$ & 1 & $0.1 \_0.2$ \\
\hline VRN2 & vernalization & 1405_536 & 3_1 & 0 & $0.2 \_0.2$ & $0 \_1(0)$ & 0_0 & 0 & 0_0 \\
\hline$F L C$ & vernalization, flowering time & 840_170 & $17 \_5$ & 2 & 2_2.9 & $9 \_5(3)$ & $0 \_0$ & 0 & 0_0 \\
\hline AGL6 & flowering time & 570_182 & $2 \_0$ & 0 & $0.4 \_0$ & 1_0 (0) & 0_0 & 0 & 0_0 \\
\hline AGL16 & flowering time & 772_182 & $9 \_1$ & $1^{d}$ & $0.3 \_0$ & 3_0 (1) & 1_0 & 0 & $0.13 \_0$ \\
\hline$A P 2$ & flowering time & 750_447 & $9 \_4$ & 2 & $1.2 \_0.9$ & $0 \_4(0)$ & 0_0 & 0 & $0 \_0$ \\
\hline SOC1 & flowering time & 797_290 & $6 \_1$ & $1^{d}$ & $0.8 \_0.3$ & 0_0 (0) & 0_0 & 0 & 0_0 \\
\hline FUL & flowering time, pod shattering & 942_295 & $3 \_0$ & 0 & $0.3 \_0$ & 1_0 (1) & 0_0 & 0 & 0_0 \\
\hline$R P L$ & flowering time, pod shattering & 560_524 & 1_1 & 1 & $0.2 \_0.2$ & 0_0 (0) & 1_1 & 1 & $0.2 \_0.2$ \\
\hline ADPG1 & pod shattering & 650_138 & 15_0 & 0 & $2.3 \_0$ & 11_0 (2) & 0_0 & 0 & 0_0 \\
\hline ADPG2 & pod shattering & 465_212 & 4_3 & 0 & $0.9 \_1.4$ & 0_0 (0) & 0_0 & 0 & 0_0 \\
\hline$A L C$ & pod shattering & 849_321 & 7_1 & 1 & $0.8 \_0.3$ & 3_0 (2) & 0_0 & 0 & 0_0 \\
\hline IND & pod shattering & $1025 \_440$ & $11 \_5$ & 3 & $1.1 \_1.1$ & $0 \_3(2)$ & 0_0 & 0 & 0_0 \\
\hline NAC012 & pod shattering & 400_305 & 1_0 & 0 & $0.3 \_0$ & 0_0 (0) & 0_0 & 0 & 0_0 \\
\hline SHP1 & pod shattering & 1112_330 & $19 \_5$ & 0 & $1.7 \_1.5$ & 0_0 (0) & $11 \_3$ & 0 & 1_0.9 \\
\hline SHP2 & pod shattering & $962 \_411$ & $15 \_6$ & 2 & 1.6_1.5 & 1_1 (1) & 1_1 & 1 & $0.1 \_0.2$ \\
\hline FAD2 & oil quality & 710_416 & $5 \_4$ & 2 & $0.7 \_1$ & 0_0 (0) & 1_1 & 1 & $0.1 \_0.2$ \\
\hline FAE1 & oil quality & 490_478 & $2 \_2$ & 0 & $0.4 \_0.4$ & $0 \_2(0)$ & 0_0 & 0 & 0_0 \\
\hline KCS8 & oil quality & 1382_1362 & 12_9 & 5 & $0.9 \_0.7$ & 0_0 (0) & 0_0 & 0 & 0_0 \\
\hline TAG1 & oil content & $962 \_414$ & $15 \_5$ & 0 & 1.6_0 & 1_0 (0) & 1_0 & 0 & $0.1 \_0$ \\
\hline WR/1 & oil content & 1738_736 & 10_3 & 1 & $0.6 \_0.4$ & 1_0 (1) & 0_0 & 0 & 0_0 \\
\hline$A G L 11$ & seed dormancy & 587_253 & 8_1 & 0 & $1.4 \_0.4$ & 1_0 (1) & 1_0 & 0 & $0.2 \_0$ \\
\hline ATG5 & plant defense & 1672_392 & 11_0 & 0 & $0.7 \_0$ & 5_0 (1) & 2_0 & 0 & $0.1 \_0$ \\
\hline FER & disease resistance & 1112_1112 & 7_7 & $1+2^{d}$ & 0.6_0.6 & $0 \_0(0)$ & $2 \_2$ & 1 & $0.2 \_0.2$ \\
\hline GTR2 & glucosinolate transport & 1200_1016 & 7_6 & $1^{d}$ & $0.6 \_0.6$ & 1_3 (4) & 0_0 & 0 & 0_0 \\
\hline HAI2 & seed dormancy & 1034_865 & $11 \_4$ & $1^{d}$ & $1.1 \_0.5$ & $1 \_1(1)$ & 0_0 & 0 & 0_0 \\
\hline Total & & 27,381_14,334 & 243_95 & 40 & & 39_22 (21) & $34 \_16$ & 9 & \\
\hline Mean & & & & & $0.9 \_0.8$ & & & & $0.14 \_0.16$ \\
\hline
\end{tabular}

${ }^{a}$ Values to the left of the underscore are for full length of the sequenced regions whereas values to the right of the underscore are only for the coding regions; ${ }^{b}$ $=$ applies only to the coding regions; ${ }^{c}=$ values within parentheses refer to the total number of polymorphisms unique to $L$. campestre; ${ }^{d}=$ polymorphism predicted as deleterious for protein function

developed by Broad Institute). These variants were subsequently used to generate individual specific consensus sequences using GATK's FastaAlternativeReferenceMaker command [48]. All chromatograms generated through resequencing of the 19 samples were visually evaluated using BioEdit version 7.0.5 [49], especially at the polymorphic sites to ensure that these sites were correctly scored. Then, multiple alignment for each of the 24 gene sequences of the 31 samples (19 samples from resequencing and 12 samples from RAD-sequencing) was performed using ClustalX version2.1 software [50], and then the sequences were manually edited using BioEdit version 7.0.5. Finally, variable sites 
in the forms of single nucleotide polymorphism (SNPs) and indels were tabulated. The same procedure was followed for the remaining six genes except that only sequences from 19 genotypes were used. The online PROVEAN tool (J. Craig Venter Institute) was used to predict the impact of the polymorphisms leading to a change in the amino acid sequence [51].

\section{Phylogenetic analyses}

Two data sets were used for phylogenetic analyses of different genotypes of three Lepidium species and their hybrids. The first data set contains polymorphism only within the coding regions of the 30 genes whereas the second data set contain polymorphism within both the coding and non-coding regions of these genes. MEGA7 [52] software was used for the phylogenetic analyses through the application of methods that include Maximum Likelihood, Neighbor-Joining, Minimum Evolution, and Maximum Parsimony. However, most of the analyses produced highly similar results and hence trees generated using the Neighbor-Joining method [53] based on the evolutionary distances calculated according to Nei and Kumar [54] are presented in this paper. The bootstrap test [55] for the robustness of the tree branches was conducted based on 10,000 replications.

\section{Results}

To identify polymorphisms that may contribute to domestication syndrome traits, perenniality and oil content and quality, partial sequences of 30 genes were analyzed in Lepidium. The protein coding sequences of field cress showed a high level of homology to A. thaliana with the sequence identity between $A$. thaliana and field cress ranging between 81 to $98 \%$ with a mean value of $89.2 \%$ (Table 2). A similar level of average sequence identity (89.3\%) was observed when comparing field cress to A. lyrata, although differences were observed in more than $50 \%$ of the genes investigated. The comparative sequence analysis with additional Brassicaceae species showed that an average sequence identity between field cress and Camelina sativa, a minor oil crop grown in Europe and North America was 88.7\%; Capsella rubella -a model plant used to study self-incompatibility in plant reproductionshowed similar level of sequence identity with field cress (88.5\%). The commercially grown agricultural and horticultural crops B. napus, B. oleracea and B. rapa shared a slightly lower sequence identity with field cress with a mean of around $86 \%$ for the coding regions.

The alignment of partial gene sequences of field cress, CHe hybrids, L. heterophyllum, and L. hirtum revealed polymorphisms in all of the analyzed gene sequences. The distribution of polymorphisms for each gene sequence are listed in Table 3. Twenty-five of the gene sequences had SNPs or indels in the predicted coding regions and 19 of the gene sequences had at least one polymorphism that lead to an altered amino acid sequence. Polymorphisms that were predicted to be deleterious for protein function were recorded in six of the genes (AGL16, FER, GTR2, HAI2, MAF5 and SOC1) (Table 3).

In total, 243 polymorphic sites were observed in 27,381 nucleotides long aligned sequences, which constitutes about $0.9 \%$ of the total analyzed nucleotides. The majority of the variations were single nucleotide substitutions but indels of variable lengths were also observed. Ninety-five of the polymorphisms were located in the predicted coding regions which constitute about $0.7 \%$ of the total length of the coding regions analyzed $(14,334 \mathrm{nt})$. None of the sequences analyzed had mutations that would lead to an obvious severe defect in the protein, such as premature STOP codon or frame-shift indels. However, 40 of the identified polymorphisms were nonsynonymous and would result in an altered protein sequence. Seven of these polymorphisms were SNPs that were predicted to be deleterious for the protein function (Table 3). Moreover, 61 of the observed polymorphisms (39 in non-coding, and 22 in coding regions) were shown to be species specific, of which 21 were unique to field cress.

Within the field cress group of 24 individuals, 34 polymorphisms were observed in 13 different genes. Sixteen of the polymorphisms were located in the predicted coding regions of the FAD2, FER, FRI, MAF2, MAF5, RPL, SHP1, SHP2 and VRN1 genes. Nine of these polymorphisms are nonsynonymous but none were predicted to have a severe impact on the protein function, according to PROVEAN. The gene sequence of SHP1 stands out by having most polymorphisms among the field cress individuals with six SNPs and two indels in the non-coding region and additionally three SNPs in the coding region. MAF2 has variable sites that accounted for $1.3 \%$ of the total nucleotides analyzed and $1.7 \%$ in coding region, which is significantly higher than the other genes in this study.

Two different data sets were used for analysis of phylogenetic relationship between the individuals representing the three Lepidium species and CHe hybrids: a data set that contains only sequences of coding regions and another one that contains sequences of both coding and non-coding regions. Cladograms generated based on both data sets showed a formation of clearly separated branches representing the different species and the hybrids with a strong bootstrap support (Figs. 1 and 2). In both cases, field cress is shown to be most closely related to $\mathrm{CHe}$ hybrids and then to L. heterophyllum. The two cladograms slightly differ in the clade that comprised the field cress individuals although both showed a clear separation of genotypes LcGre2 and LcSma from the rest. Three genotypes (LcGer1, LcSlj and LcSsk), two of which represent Sweden and one represents Germany, 


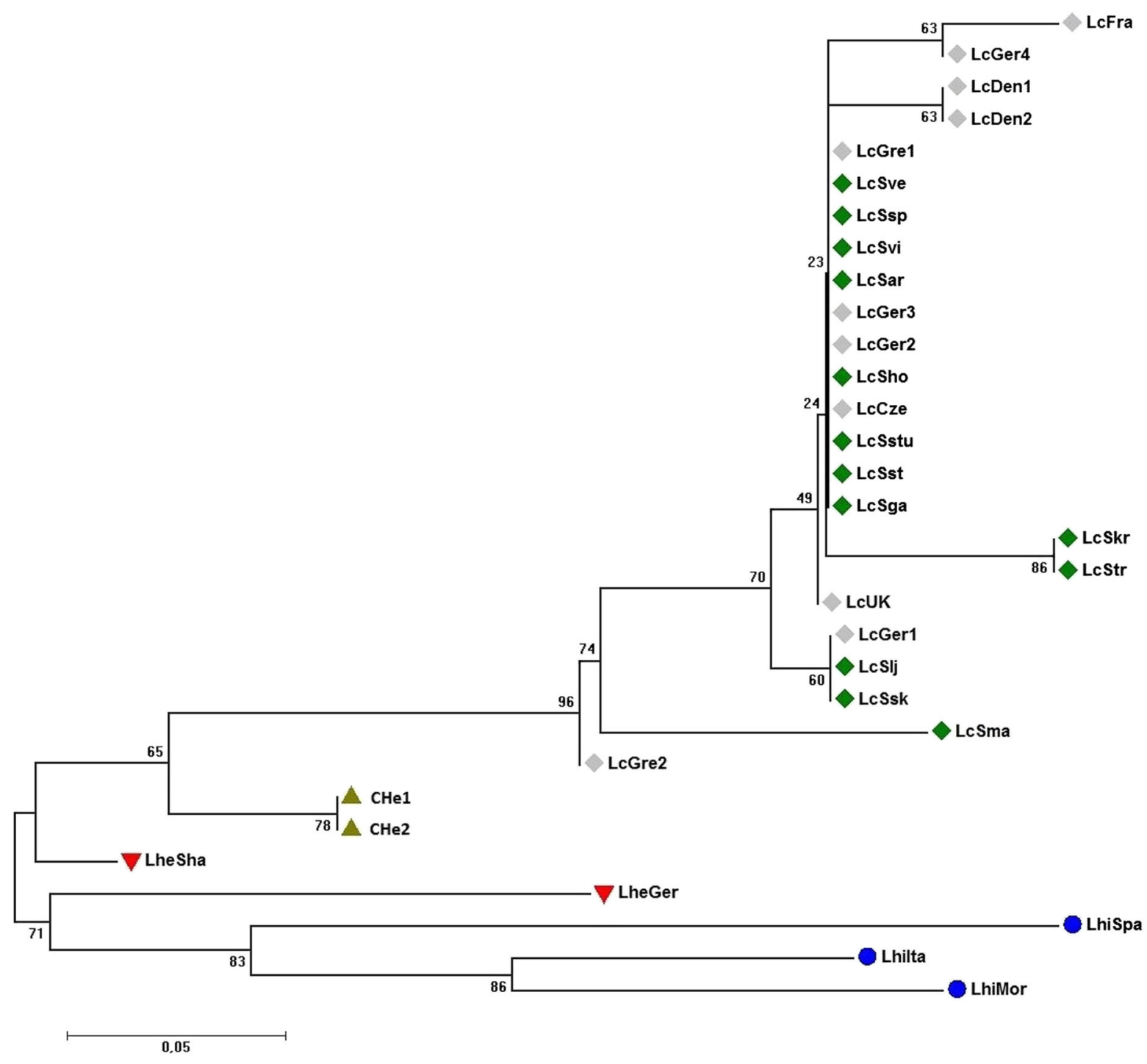

Fig. 1 Cladogram showing the clustering pattern of individual genotypes representing field cress, CHe hybrids, L. heterophyllum and L. hirtum based on polymorphisms in coding regions. Green diamonds denote field cress accessions collected in Sweden and grey diamonds field cress from other parts of Europe. Green triangles $=$ CHe hybrids, red triangles $=L$. heterophyllum and blue circles $=L$. hirtum. Numbers at the base of branches are bootstrap values

formed a separate branch with a moderate level of bootstrap support in both data set. The use of combined data of coding and non-coding sequences produced a better resolution in this clade although some of the branches were supported by low bootstrap values, which is mainly because of low sequence divergence between the different genotypes of field cress.

\section{Discussion}

Sequence homology between various genes of field cress and other Brassicaceae species

Comparative genomics is a powerful tool that facilitates our understanding of the genetics of poorly studied plant species based on data from a closely related well-studied species. The close evolutionary relationship between field cress and the extensively studied model plant $A$. thaliana is advantageous and will be highly valuable for the domestication and further breeding of field cress. Alignments of the coding regions of the 30 genes confirm the close phylogenetic relationship between these two species. Comparing the mean sequence identity of the 30 genes suggests that Lepidium is more closely related to Arabidopsis than to Brassica (Table 2). The data also suggests closer evolutionary relationship of Lepidium with Camelina and Capsella than with Brassica. This finding correlates well with the recently released phylogeny of the Brassicaceae family using 113 nuclear DNA markers [56]. 


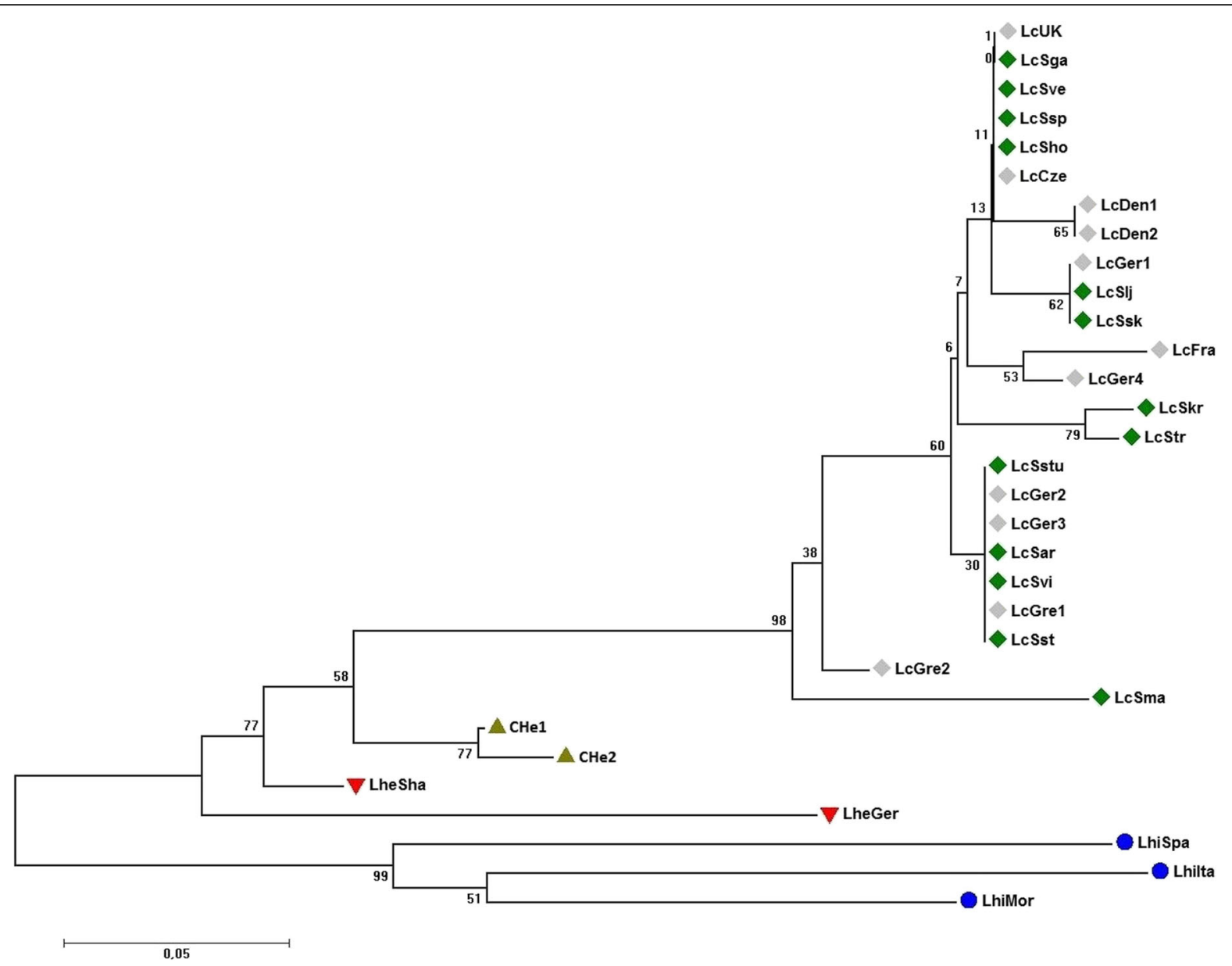

Fig. 2 Cladogram showing the clustering pattern of individual genotypes representing field cress, CHe hybrids, L. heterophyllum and L. hirtum based on polymorphisms in both coding- and noncoding regions. Green diamonds denote field cress accessions collected in Sweden and grey diamonds field cress from other parts of Europe. Green triangles $=C$ He hybrids, red triangles $=L$. heterophyllum and blue circles $=L$. hirtum .

Numbers at the base of branches are bootstrap values

Many of the genes that are regulating flowering time and vernalization have more than $90 \%$ sequence identity to the Arabidopsis counterpart in this study (Table 2). Moreover, the top three genes with the highest level of polymorphisms per nucleotide in the coding regions (FLC, FRI and MAF5) also belong to this group of traits. However, in this group of genes, FRI stands out as one of the least conserved genes as it has a lower level of sequence homology to the other species it was compared with and has a relatively high level of variation in the coding region. Thus, this result suggests that FRI is evolving faster than most of the other genes analyzed in this study. Although FRI has been attributed to play a major role in response to vernalization and controlling flowering time in A. thaliana, the function of this gene in other species such as A. lyrata seems to be of less importance [57]. The role of FRI has not been completely elucidated for B. rapa, B. napus and B. oleracea, but it seems to have a less pronounced role in flowering time than in A. thaliana [58].

\section{Sequence variation in various genes between and within Lepidium species}

Our genomic data showed that field cress is more closely related to L. heterophyllum than to L. hirtum (Figs. 1 and 2 ), which is in agreement with previous research based on chloroplast DNA analysis [59]. Field cress is a self-fertilizing plant, and as inbred populations they are expected to have low within-population variation. Hence, the clustering pattern of the genotypes (Figs. 1 and 2) clearly show lack of population differentiation in field cress according to geographical origin within Europe. Genotypes representing Sweden and other parts of Europe are distributed across the sub-branches within the field cress branch. This is similar to what was previously reported for $A$. thaliana; i.e., lacking a clear branching of 
different ecotypes, and only significant isolation by distance -such as separate continents- divides populations into distinct clusters [60]. However, the addition of considerably more DNA markers and screening of additional individuals have altered this hypothesis and clear global population structures seem to exist for A. thaliana [61]. In this study, only 24 field cress genotypes and short segments of the 30 genes were analyzed. Hence to reach a firm conclusion regarding the lack of population structure in European field cress populations, the use of additional polymorphic DNA markers and genotyping more individuals may be necessary.

The genotype LcGre2 differentiated from the main body of the field cress genotypes (Figs. 1 and 2). This genotype is of particular interest as it is more resistant to pod shattering and has a higher oil content compared to other field cress genotypes (unpublished data). It carries two mutations in the non-coding part of the SHP1 gene which makes it different from all other field cress genotypes included in the present study, and which may be linked to mutation(s) in the coding region of this gene that confer shattering resistance. However, no mutations were found in the genes that encode for oil content and quality, and hence sequencing the full coding regions of these genes is needed to identify any useful mutations. One synonymous and one nonsynonymous mutation in the coding regions that contributed to the separation of this genotype from other field cress genotypes were found in the FRI gene, which regulates vernalization. No distinct vernalization requirement or winter hardiness were observed for the accession from which this genotype was developed. Multi-environment field trials are needed to determine the effect of these mutations. Similarly, LcSmar, a relatively high seed yielding genotype, was also clearly separated from the field cress cluster and have several mutations in the coding regions of FRI, VRN1 and MAF5, which are genes regulating vernalization. This genotype has a unique SNP mutation in FRI, which is of particular interest. Hence, it will be very interesting to see how this accession perform in upcoming field trials held in the northern part of Sweden. In our ongoing crossbreeding experiments, hybridization of some field cress genotypes results in $F_{1}$ hybrids with strong hybrid vigor, and some recombinant inbred lines derived from such hybrids maintain their vigor. On the other hand, some crosses result in weak $F_{1}$ hybrids and subsequent generations. Hence, the clustering pattern of the 24 field cress genotypes in the present study facilitates the designing of an efficient crossbreeding scheme to identify best pairs of genotypes in terms of their combining ability.

Genetic variation was found in all analyzed genes but a higher level of polymorphisms was observed in the coding regions of genes regulating flowering time, vernalization and pod shattering. This result could be explained by the fact that individual plants displaying clear phenotypic differences for these traits were intentionally included in this study. A number of polymorphic sites among the three Lepidium species in the genes regulating oil content and quality was observed, but only two polymorphisms were observed within the field cress for these genes, whereof one is an indel in $F A D 2$ causing a deletion of a serine residue in two of the field cress genotypes. Field cress has generally a higher oil content, with average of about $20 \%$, than the other two Lepidium species, with average about 15\% (unpublished data). Hence further analysis of the variations within these genes followed by well-thought crossbreeding may lead to an increase in oil content in field cress.

Flowering time is one of the most important agronomic traits and is preceded by a vernalization period in perennial, biennial and winter type annual plants. Timing of flowering at the most favorable conditions is important to optimize the seed production in a crop. Vernalization ensures that the frost-sensitive transition from vegetative to reproductive growth to occur at milder temperatures. In this study, 13 gene sequences related to flowering time and vernalization were analyzed for natural variation and compared with other closely related species in terms of sequence homology. This group of genes show the highest level of variation in the sequenced coding regions, compared to the genes coding for other traits considered in this study. FLC, $M A F 5, M A F 2$ and FRI come on top as per their polymorphisms per nucleotide in the protein coding regions (Table 3), suggesting that they are the fastest evolving genes, in that order, when compared to other genes. Lepidium FRI also has a lower sequence homology to $A$. thaliana FRI (AtFRI), compared to other genes in this study except ATG5, which has the same level of homology. In this gene, a high degree of variation between the biennial species (field cress) and the perennial species (L. heterophyllum and L. hirtum) was observed, thus the genetic variation between the two groups could be linked to perenniality.

The transition between vegetative and reproductive phase is mainly controlled by $F L C$ and its positive regulator FRI. In fact, polymorphisms in these genes account for most of the natural variation found in flowering time in A. thaliana [62]. Several naturally occurring non-functional AtFRI alleles have been reported and the majority of them derive from deletions in the protein coding region [17, 62]. Six nonsynonymous SNPs were observed in the FRI sequence among the three Lepidium species but no polymorphisms resulting in a deletion of amino acid sequence was found. Our data shows a high level of polymorphisms in the FRI gene, both in coding and non-coding sequences. This finding may indicate that FRI does not have a dominant role in the biennial 
field cress as it has been shown that FRI has a redundant function in A. lyrata, which has a perennial life cycle [57]. As mentioned above, the sequence homology for the coding sequences of the FRI gene is higher between field cress and $A$. lyrata (84\%) than between field cress and $A$. thaliana (81\%). However, the homology is basically the same for both pairs at the protein level.

Multiple studies in A. thaliana failed to find any nonsynonymous polymorphisms in the AtFLC gene. Of the few polymorphisms found, the majority were located in the first intron [63]. One of these polymorphisms separate AtFLC alleles into two distinct haplogroups that flowers at significantly different times in a null-FRI background [64]. The low abundance of polymorphisms in the coding region of $A t F L C$ is in line with our findings in the partial sequences of field cress $F L C$ gene, as no variation was detected among the field cress genotypes. However, among the three Lepidium species FLC had one of the highest number of polymorphisms per nucleotides, both in coding and non-coding regions. Hence, although this gene seems to be conserved within the field cress, a high level of diversity between closely related Lepidium species is apparent. On the other hand, the sequence identity between field cress and several Brassicaceae species was overall high with a sequence identity of 88 to $92 \%$ for the coding sequence of this gene (Table 2). The FLC gene in A. lyrata has been tandemly duplicated and one of the paralogs are having a more pronounced effect on vernalization than the other $[65,66]$. Two separate partial sequences of the field cress $F L C$ gene were sequenced in this project, targeting the $5^{\prime}$ and $3^{\prime}$ regions of the coding sequence. A nucleotide BLAST search shows that the $5^{\prime}$ region is more similar to the $F L C 2$ gene in A. lyrata, whilst the $3^{\prime}$ region is more homologous to the FLC1 gene. Hence it cannot be ruled out that there are more than one copy of the $F L C$ gene in field cress, and that we have targeted both paralogs.

Downregulation of $F L C$ promotes floral development while low levels of $F L C$ are maintained after cold treatment by VRN1 and VRN2 in Arabidopsis, which are serving as a molecular memory of the vernalization [21, 67]. Interestingly, compared to other genes included in this study, an extremely high level of polymorphisms has been reported for AtVRN2, over 140 mutations in the UTR and introns, and 55 in the coding region, resulting in $4 \%$ of the nucleotides in the coding region being polymorphic [68]. Even though $536 \mathrm{nt}$ long coding sequences of Lepidium VNR2 were analyzed, only one SNPs was observed among the three Lepidium species. Thus, less than $0.2 \%$ of the nucleotides in this region are variable. When delimiting the observed polymorphisms of AtVRN2 to the corresponding region to this $536 \mathrm{nt}$ long segment, and recalculating based on this, it seems as this region is less variable than other parts of the gene as only $2 \%$ of the nucleotides are polymorphic in $A$. thaliana. However, that is still ten times more variable than in Lepidium. Hence, the VRN2 gene appears to be more conserved within the Lepidium species than in $A$. thaliana. Moreover, very few polymorphisms were observed in VRN1 among the Lepidium species in this study, but this is more in line with what have been reported for the Arabidopsis ortholog.

$S O C 1$ is an integrator of the floral pathway under direct repression of FLC. FUL is a MADS box gene that operates downstream of $S O C 1$ in the same pathway. Perenniality is normally considered to be a complex trait. However, a double null mutant of FUL and SOC1 could transform an annual Arabidopsis into something that is reminiscent of a perennial plant [24]. While the controls senesced after flowering, the FUL/SOC1 mutant plant returned to vegetative stage and eventually developed into a highly-branched shrub with woody stems, which are traits associated with perennials. Moreover, expression levels of $F U L$ and $S O C 1$ are significantly reduced in the A. thaliana ecotype SY-0, which has a similar morphology as the FUL/SOC1 mutant [69]. This indicate that $S O C 1$ and FUL genes may be important in controlling longevity in a plant. Only a single nonsynonymous polymorphisms have been reported for AtFUL and none for AtSOC1 [68]. Such a result is comparable with our findings in the three Lepidium species, in which we only found one missense mutation that differentiates $L$. hirtum ssp. atlanticum from field cress, L. heterophyllum and the other two subspecies of L. hirtum in SOC1 and none in FUL. Hence, this mutation cannot be attributed to perenniality trait. Lepidium FUL and SOC1 also share a very high sequence homology with AtFUL and AtSOC1, thus indicating that these genes are highly conserved. The difference in regulation of these genes, rather than polymorphism within the coding gene sequence, is therefore likely to be the cause of the observed phenotypic variation in the double mutant of $F U L$ and SOC1, and the difference in longevity for field cress versus its perennial relatives.

For wild plants, it is generally advantageous to disperse all seeds to increase the survival chances of future generations. In contrast, domesticated plants are more resistant against shattering which ensures farmers' maximum seed harvest. Resistance to pod shattering and seed dispersal is an important agronomic trait as shattering can result in serious yield losses. In Arabidopsis, the seed-containing fruit is an ovary composed of three main tissue types: the valve, the replum and the valve margin. The valve margin separates the valve from the replum and also referred to as the dehiscence zone. Upon fruit dehiscence, the valve margin detaches from the replum and the seeds are released. The two 
transcription factor genes ( $A L C$ and $I N D)$ are required for valve margin formation and are promoted by MADS box genes SHP1 and SHP2 [31-33]. ALC, IND, SHP1 and $S H P 2$ are collectively known as the valve identity genes. FUL and RPL genes are expressed in the valve and replum respectively and negatively regulates the valve identity genes to ensure that these genes are expressed in the proper tissue [30,34]. Many aspects of fruit dehiscence have been studied in field cress. There is a high degree of conservation of the fruit development pathways between field cress and Arabidopsis and expression levels of the field cress valve identity genes resembles those of $A$. thaliana [12, 70] Many of the genes involved in seed shattering displayed a relatively high level of variation per nucleotides in this study. This mirrors the phenotypic variation in this particular trait among the field cress genotypes in the present study (unpublished data).

The SHP1, ADPG2, IND pod shattering genes analyzed in Lepidium also had a higher level of variation in the coding region per nucleotides $(1.1-1.5 \%)$ than the average variation for all genes obtained in this study. The sequences of ADPG2 and IND also are less similar to the A. thaliana counterparts ( 84 and $85 \%$, respectively), thus indicating that these genes are not as conserved as most other genes in this study. A nonsynonymous mutation in $R P L$ divided the field cress individuals into two groups, where the individuals having one of the alleles display medium to high level of pod shattering while those having the other allele have a lower tendency towards shattering. RPL has proven to be an important regulator of this trait in $B$. rapa, as well as in Oryza sativa as a single point mutation in the regulatory sequence of this gene seems to be responsible for seed shattering resistance [71, 72]. The shattering type allele is present in A. thaliana as well as in field cress which is naturally highly shattering [73].

Seeds with a high oil content and a desirable oil composition is essential for developing an economically viable oilseed crop. Partial sequences of Lepidium that are orthologous to Arabidopsis FAD2, FAE1, WRI1, TAG1 and KCS8 which are all involved in fatty acid biosynthesis were analyzed in this study. Much of the natural variation in seed oil composition in Arabidopsis has been attributed to FAD2 and FAE1 [74]. Indeed, downregulation of $F A D 2$ and $F A E 1$ in field cress also results in altered oil composition, drastically increasing the proportion of desirable oleic acid in the oil [75]. All the five genes shared high homology to the Arabidopsis orthologs and nonsynonymous polymorphisms were observed in FAD2, KCS8 and WRI1. One of the nonsynonymous SNPs was located in the start codon of the predicted amino acid sequence of KCS8. This allelic difference only results in a five amino-acid shortening of the protein as an additional in-frame start codon is positioned close by. Moreover, this shortening was not predicted to have a severe effect on the final protein according to PROVEAN. In FAE1 there are two SNPs in the coding region differentiating field cress from the $L$. heterophyllum and L. hirtum. As field cress has a relatively higher oil content than the other two Lepidium species these polymorphism could be important markers for this trait.

The immediate challenges of breeding field cress into an economically viable new perennial oil crop includes countering unstable longevity and weak shattering resistance, and increasing the oil content $[9,73]$. In this study, we have characterized partial sequences of the genes regulating these traits. The continuation of the work includes identifying the full gene sequences and characterize them. In future research, it would be necessary to include cis-regulatory elements as there are examples of important polymorphisms in these regions responsible for the traits that are associated with the "domestication syndrome" [71]. Linkage mapping, and detailed quantitative trait loci maps, which are in progress at the moment, will also be needed to advance the breeding of field cress. Furthermore, the agronomic practice for perennial crops is not fully developed, which is also the case for field cress.

With these findings, we have begun to unravel the genomics of field cress and the results will be the foundation for the future breeding strategy of this potential oilseed crop. Moreover, the outcome of this study has contributed to the overall understanding of Lepidium genome evolution.

\section{Conclusion}

This study is the first performed on Lepidium genes with the purpose of improving field cress as a future oilseed crop. It has revealed significant variation among the Lepidium species within the partial sequences of 30 genes known to regulate traits such as flowering, perenniality, pod shattering and more. The phylogenetic relationship demonstrated between the three Lepidium species in this study can guide the development of interspecific hybridization to advance the domestication process of field cress.

\section{Additional files}

Additional file 1: Table S1. Genomic DNA sequences. (XLSX $23 \mathrm{~kb}$ )

Additional file 2: Table S2. List of genes, accession numbers and primer sequences. (DOCX $36 \mathrm{~kb}$ )

\section{Abbreviations}

ADPG 1/2: ARABIDOPSIS DEHISCENCE ZONE POLYGALACTURONASE1/2 gene; AGL11: AGAMOUS-LIKE 11 gene; AGL 16: AGAMOUS LIKE 16 gene;

AGL6: AGAMOUS LIKE 6 gene; ALC: ALCATRAZ gene; AP2: APETALA2 gene; 
At: Arabidopsis thaliana; ATG5: AUTOPHAGY RELATED 5 gene; BLAST: Basic local alignment search tool; $\mathrm{CHe}$ hybrids: Lepidium campestre- Lepidium heterophyllum hybrids; FAD2: FATTY ACID DESATURASE 2 gene; FAE1: FATTY ACID ELONGATION 1 gene; FER: FERONIA gene; FLC: FLOWERING LOCUS C gene; FRI: FRIGIDA gene; FUL: FRUITFULL gene; HAI2: HIGHLY ABA-INDUCED PP2C PROTEIN 2 gene; IND: INDEHISCENT gene; KCS8: 3-KETOACYL-COASYNTHASE 8 gene; LC: Lepidium campestre; MADS box: MINICHROMOSOME MAINTENANCE1, AGAMOUS, DEFICIENS and SERUM RESPONSE FACTOR bOX; MAF2-5: MADS AFFECTING FLOWERING 2-5 genes; NAC012: NAC DOMAIN CONTAINING PROTEIN 12 gene; Nt: nucleotides; RAD: Restriction site associated DNA; RPL: REPLUMLESS gene; SHP1/2: SHATTERPROOF1/2 genes; SNP: Single nucleotide polymorphism; SOC1: SUPRESSOR OF OVEREXPRESSION OF CO1 gene; TAG1: ACYL-COA: DIACYLGLYCEROL ACYLTRANSFERASE 1 gene; VIN3: VERNALIZATION INSENSITIVE 3 gene; VRN1/2: REDUCED VERNALIZATION RESPONSE1/2 gene; WRI1: WRINKLED 1 gene

\section{Acknowledgements}

We would like to thank PlantLink for bioinformatics support. The authors would also like to acknowledge Professor Dirk-Jan De Koning for his major role in the RAD-sequencing project within Component Project-2 (CP2) of Mistra Biotech research program.

\section{Funding}

This work is financed by grants from the Swedish Foundation for Strategic Research (SSF), the Swedish Foundation for Strategic Environmental Research (MISTRA) and Swedish University of Agricultural Sciences (SLU).

\section{Availability of data and materials}

Lepidium campestre genomic sequences homologous to Arabidopsis genes that were derived from RAD-sequencing and used in this study is provided in Additional file 1: Table S1. Representative partial sequences of the 30 genes were submitted to GenBank and their accession number is provided in Additional file 2: Table S2. Aligned partial sequences of the genes for all samples used in this study can be obtained by contacting the corresponding author.

\section{Authors' contributions}

$M G$ and $R O$ secured the funding; $C G, M G$ and $R O$ conceived and designed the study; CG and FLP obtained the data; CG, MG, FLP and JW analyzed the data; CG and MG wrote the paper; and FLP, JW and RO revised the paper. All authors read and approved the final manuscript.

\section{Ethics approval and consent to participate}

The plant materials used in this study were derived from accessions obtained from Gene Banks and Botanical Gardens as well as from newly collected populations. These materials are permitted to be used for this study.

\section{Competing interests}

The authors declare that they have no competing interests.

\section{Publisher's Note}

Springer Nature remains neutral with regard to jurisdictional claims in published maps and institutional affiliations.

\section{Author details}

${ }^{1}$ Department of Plant Breeding, Swedish University of Agricultural Sciences, Box 101, SE-23053 Alnarp, Sweden. '2Department of Plant Protection Biology, Swedish University of Agricultural Sciences, Box 102, SE-23053 Alnarp, Sweden. ${ }^{3}$ Department of Animal Breeding and Genetics, Swedish University of Agricultural Sciences, Box 7023, SE-750 07 Uppsala, Sweden.

Received: 26 September 2017 Accepted: 18 May 2018

Published online: 29 May 2018

\section{References}

1. Doebley JF, Gaut BS, Smith BD. The molecular genetics of crop domestication. Cell. 2006;127:1309-21.

2. Randall GW, Mulla DJ. Nitrate nitrogen in surface waters as influenced by climatic conditions and agricultural practices. J Environ Qual. 2001;30:337-44.

3. DeHaan LR, Wang S, Larson SR, Cattani DJ, Zhang X, Viinanen T. Current efforts to develop perennial wheat and domesticate Thinopyrum intermedium as a perennial grain. In: Batello C, Wade L, Cox S, Pogna N, Bozzini A, Choptiany J, editors. Perennial crops for food security. Proceedings of the FAO expert workshop. Rome, Italy; 28-30 august; 2013. p. 72-89.

4. Sacks E. Perennial rice: challenges and opportunities. In: Batello C, Wade L, Cox S, Pogna N, Bozzini A, Choptiany J, editors. Perennial crops for food security. Proceedings of the FAO expert workshop. Rome, Italy; 28-30 august; 2013. p. 16-26

5. Kantar MB, Betts K, Michno JM, Luby JJ, Morrell PL, Hulke BS, Stupar RM, Wyse DL. Evaluating an interspecific Helianthus annuus $x$ Helianthus tuberosus population for use in a perennial sunflower breeding program. Field Crop Res. 2014;155:254-64.

6. Rice A, Glick L, Abadi S, Einhorn M, Kopelman NM, Salman-Minkov A, Mayzel J, Chay O, Mayrose I. The chromosome counts database CCDB; - a community resource of plant chromosome numbers. New Phytol. 2015;206:19-26.

7. Geleta M, Zhu L-H, Stymne S, Lehrman A, Hansson S-O. Domestication of Lepidium campestre as part of Mistra biotech, a research programme focused on agro biotechnology for sustainable food. In: Batello C, Wade L, Cox S, Pogna N, Bozzini A, Choptiany J, editors. Perennial crops for food security. Proceedings of the FAO expert workshop. Rome, Italy, 28-30 august; 2013. p. 141-7.

8. Lee J, Mummenhoff K, Bowman J. Allopolyploidization and evolution of species with reduced floral structures in Lepidium L. (Brassicaceae). Proc Natl Acad Sci U S A. 2002;99(26):16835-40.

9. Andersson A, Merker A, Nilsson P, Sörensen H, Åman P. Chemical composition of the potential new oilseed crops Barbarea vulgaris, Barbarea verna and Lepidium campestre. J Sci Food Agric. 1999;79:179-86.

10. Merker A, Eriksson D, Bertholdsson N-O. Barley yield increases with undersown Lepidium campestre. Acta Agric Scand Sect B. 2010;60:269-73.

11. Ivarson E, Ahlman A, Li X, Zhu LH. Development of an efficient regeneration and transformation method for the new potential oilseed crop Lepidium campestre. BMC Plant Biol. 2013;13:115.

12. Lenser $\mathrm{T}$, Theissen $\mathrm{G}$. Conservation of fruit dehiscence pathways between Lepidium campestre and Arabidopsis thaliana sheds light on the regulation of INDEHISCENT. Plant J. 2013;76:545-56.

13. Arabidopsis Genome I. Analysis of the genome sequence of the flowering plant Arabidopsis thaliana. Nature. 2000;408:796-815.

14. Genomes Consortium, Nordborg, M, et al. 1,135 genomes reveal the global pattern of polymorphism in Arabidopsis thaliana. Cell. 2016; 166:481-91.

15. Michaels SD, Amasino RM. FLOWERING LOCUS C encodes a novel MADS domain protein that acts as a repressor of flowering. Plant Cell. 1999;11:949-56.

16. Sheldon CC, Rouse DT, Finnegan EJ, Peacock WJ, Dennis ES. The molecular basis of vernalization: the central role of FLOWERING LOCUS C FLC. Proc Natl Acad Sci U S A. 2000;97:3753-8.

17. Johanson U, West J, Lister C, Michaels S, Amasino R, Dean C. Molecular analysis of FRIGIDA, a major determinant of natural variation in Arabidopsis flowering time. Science. 2000;290:344-7.

18. Koornneef M, Blankestijndevries H, Hanhart C, Soppe W, Peeters T. The phenotype of some late-flowering mutants is enhanced by a locus on chromosome-5 that is not effective in the Landsberg erecta wild-type. Plant J. 1994;6:911-9.

19. De Lucia F, Crevillen P, Jones AM, Greb T, Dean C. A PHD-polycomb repressive complex 2 triggers the epigenetic silencing of FLC during vernalization. Proc Natl Acad Sci U S A. 2008;105:16831-6.

20. Sung S, Amasino RM. Vernalization in Arabidopsis thaliana is mediated by the PHD finger protein VIN3. Nature. 2004;427:159-64.

21. Gendall AR, Levy YY, Wilson A, Dean C. The VERNALIZATION 2 gene mediates the epigenetic regulation of vernalization in Arabidopsis. Cell. 2001;107:525-35.

22. Hempel FD, Weigel D, Mandel MA, Ditta G, Zambryski PC, Feldman L, Yanofsky MF. Floral determination and expression of floral regulatory genes in Arabidopsis. Development. 1997;124:3845-53.

23. Lee H, Suh SS, Park E, Cho E, Ahn JH, Kim SG, Lee JS, Kwon YM, Lee I. The AGAMOUS-LIKE 20 MADS domain protein integrates floral inductive pathways in Arabidopsis. Genes Dev. 2000;14:2366-76.

24. Melzer S, Lens F, Gennen J, Vanneste S, Rohde A, Beeckman T. Floweringtime genes modulate meristem determinacy and growth form in Arabidopsis thaliana. Nat Genet. 2008;40:1489-92.

25. Hu JY, Zhou Y, He F, Dong X, Liu LY, Coupland G, Turck F, de Meaux J. miR824-regulated AGAMOUS-LIKE16 contributes to flowering time repression in Arabidopsis. Plant Cell. 2014;26:2024-37. 
26. Koo SC, Bracko O, Park MS, Schwab R, Chun HJ, Park KM, Seo JS, Grbic V, Balasubramanian S, Schmid M, Godard F, Yun DJ, Lee SY, Cho MJ, Weigel D, Kim MC. Control of lateral organ development and flowering time by the Arabidopsis thaliana MADS-box gene AGAMOUS-LIKE6. Plant J. 2010;62:807-16.

27. Ratcliffe OJ, Kumimoto RW, Wong BJ, Riechmann JL. Analysis of the Arabidopsis MADS AFFECTING FLOWERING gene family: MAF2 prevents vernalization by short periods of cold. Plant Cell. 2003;15:1159-69.

28. Yoo SK, WU X, Lee JS, Ahn JH. AGAMOUS-LIKE 6 is a floral promoter that negatively regulates the FLC/MAF clade genes and positively regulates $F T$ in Arabidopsis. Plant J. 2011;65:62-76.

29. Ferrandiz C, Liljegren SJ, Yanofsky MF. Negative regulation of the SHATTERPROOF genes by FRUITFULL during Arabidopsis fruit development. Science. 2000;289:436-8

30. Gu Q, Ferrandiz C, Yanofsky MF, Martienssen R. The FRUITFULL MADS-box gene mediates cell differentiation during Arabidopsis fruit development. Development. 1998:125:1509-17.

31. Liljegren SJ, Ditta GS, Eshed Y, Savidge B, Bowman JL, Yanofsky MF. SHATTERPROOF MADS-box genes control seed dispersal in Arabidopsis. Nature. 2000;404:766-70.

32. Liljegren SJ, Roeder AH, Kempin SA, Gremski K, Ostergaard L, Guimil S, Reyes DK, Yanofsky MF. Control of fruit patterning in Arabidopsis by INDEHISCENT. Cell. 2004;116:843-53.

33. Rajani S, Sundaresan V. The Arabidopsis myc/bHLH gene ALCATRAZ enables cell separation in fruit dehiscence. Curr Biol. 2001;11:1914-22.

34. Roeder AH, Ferrandiz C, Yanofsky MF. The role of the REPLUMLESS homeodomain protein in patterning the Arabidopsis fruit. Curr Biol. 2003;13:1630-5.

35. Ogawa M, Kay P, Wilson S, Swain SM. ARABIDOPSIS DEHISCENCE ZONE POLYGALACTURONASE1 ADPG1, ADPG2, and QUARTET2 are polygalacturonases required for cell separation during reproductive development in Arabidopsis. Plant Cell. 2009;21:216-33.

36. Zhong $\mathrm{R}$, Richardson EA, Ye ZH. Two NAC domain transcription factors, SND1 and NST1, function redundantly in regulation of secondary wall synthesis in fibers of Arabidopsis. Planta. 2007;225:1603-11.

37. Focks N, Benning C. wrinkled1: a novel, low-seed-oil mutant of Arabidopsis with a deficiency in the seed-specific regulation of carbohydrate metabolism. Plant Physiol. 1998;118:91-101.

38. Jako C, Kumar A, Wei Y, Zou J, Barton DL, Giblin EM, Covello PS, Taylor DC Seed-specific over-expression of an Arabidopsis cDNA encoding a diacylglycerol acyltransferase enhances seed oil content and seed weight. Plant Physiol. 2001;126:861-74.

39. Routaboul JM, Benning C, Bechtold N, Caboche M, Lepiniec L. The TAG1 locus of Arabidopsis encodes for a diacylglycerol acyltransferase. Plant Physiol Biochem. 1999;37:831-40.

40. Costaglioli P, Joubes J, Garcia C, Stef M, Arveiler B, Lessire R, Garbay B. Profiling candidate genes involved in wax biosynthesis in Arabidopsis thaliana by microarray analysis. Biochim Biophys Acta. 2005;1734:247-58

41. James DW Jr, Lim E, Keller J, Plooy I, Ralston E, Dooner HK. Directed tagging of the Arabidopsis FATTY ACID ELONGATION1 FAE1; gene with the maize transposon activator. Plant Cell. 1995;7:309-19.

42. Okuley J, Lightner J, Feldmann K, Yadav N, Lark E, Browse J. Arabidopsis FAD2 gene encodes the enzyme that is essential for polyunsaturated lipid synthesis. Plant Cell. 1994;6:147-58.

43. Kessler SA, Shimosato-Asano H, Keinath NF, Wuest SE, Ingram G, Panstruga $\mathrm{R}$, Grossniklaus U. Conserved molecular components for pollen tube reception and fungal invasion. Science. 2010;330:968-71.

44. Kim W, Lee Y, Park J, Lee N, Choi G. HONSU, a protein phosphatase 2C, regulates seed dormancy by inhibiting ABA signaling in Arabidopsis. Plant Cell Physiol. 2013;54:555-72.

45. Lenz HD, Haller E, Melzer E, Gust AA, Nurnberger T. Autophagy controls plant basal immunity in a pathogenic lifestyle-dependent manner. Autophagy. 2011;7:773-4.

46. Mizzotti C, Ezquer I, Paolo D, Rueda-Romero P, Guerra RF, Battaglia R, Rogachev I, Aharoni A, Kater MM, Caporali E, Colombo L. SEEDSTICK is a master regulator of development and metabolism in the Arabidopsis seed coat. PLoS Genet. 2014;10:e1004856

47. Lopes-Pinto F, Vanhala T, Geleta M, Risse J, Nichols J, Karim Gharbi K, de Koning DJ. RAD sequencing of diverse accessions of Lepidium campestre, a target species for domestication as a novel oil crop. San Diego, CA, USA: Plant and animal genome conference XXIV; 2016. p. 09-13.
48. McKenna A, Hanna M, Banks E, Sivachenko A, Cibulskis K, Kernytsky A, Garimella K, Altshuler D, Gabriel S, Daly M, DePristo MA. The genome analysis toolkit: a MapReduce framework for analyzing next-generation DNA sequencing data. Genome Res. 2010;20:1297-303.

49. Hall T. BioEdit 7.0.5. North Carolina State University. 2005.

50. Larkin MABG, Brown NP, Chenna R, McGettigan PA, McWilliam H, Valentin F, Wallace IM, Wilm A, Lopez R, Thompson JD, Gibson TJ, Higgins DG. Clustal $W$ and Clustal X version 2.0. Bioinformatics. 2007;23:2947-8.

51. Choi Y, Sims GE, Murphy S, Miller JR, Chan AP. Predicting the functional effect of amino acid substitutions and indels. PLoS One. 2012;7:e46688.

52. Kumar S, Stecher G, Koichiro Tamura K. MEGA7: molecular evolutionary genetics analysis version 7.0 for bigger datasets. Mol Biol Evol. 2016;33:1870-4.

53. Saitou N, Nei M. The neighbor-joining method: a new method for reconstructing phylogenetic trees. Mol Biol Evol. 1987;4:406-25.

54. Nei M, Kumar S. Molecular evolution and phylogenetics. New York: Oxford University Press; 2000.

55. Felsenstein J. Confidence limits on phylogenies: an approach using the bootstrap. Evolution. 1985;39:783-91.

56. Huang CH, Sun R, Hu Y, Zeng L, Zhang N, Cai L, Zhang Q, Koch MA, AlShehbaz I, Edger PP, Pires JC, Tan DY, Zhong Y, Ma H. Resolution of Brassicaceae phylogeny using nuclear genes uncovers nested radiations and supports convergent morphological evolution. Mol Biol Evol. 2016;33:394-412.

57. Kuittinen H, Niittyvuopio A, Rinne P, Savolainen O. Natural variation in Arabidopsis lyrata vernalization requirement conferred by a FRIGIDA indel polymorphism. Mol Biol Evol. 2008;25:319-29.

58. Fadina OA, Khavkin EE. The vernalization gene FRIGIDA in cultivated Brassica species. Russ J Plant Physiol. 2014;61:309-17.

59. Mummenhoff K, Bruggemann H, Bowman JL. Chloroplast DNA phylogeny and biogeography of Lepidium Brassicaceae. American J Bot. 2001;88:2051-63.

60. Sharbel TF, Haubold B, Mitchell-Olds T. Genetic isolation by distance in Arabidopsis thaliana: biogeography and postglacial colonization of Europe. Mol Ecol. 2000:9:2109-18.

61. Nordborg M, Hu TT, Ishino Y, Jhaveri J, Toomajian C, Zheng H, Bakker E, Calabrese P, Gladstone J, Goyal R, Jakobsson M, Kim S, Morozov Y, Padhukasahasram B, Plagnol V, Rosenberg NA, Shah C, Wall JD, Wang J, Zhao K, Kalbfleisch T, Schulz V, Kreitman M, Bergelson J. The pattern of polymorphism in Arabidopsis thaliana. PLoS Biol. 2005;3:e196.

62. Corre VL. Variation at two flowering time genes within and among populations of Arabidopsis thaliana: comparison with markers and traits. Mo Ecol. 2005;14:4181-92.

63. Mendez-Vigo B, Pico FX, Ramiro M, Martinez-Zapater JM, Alonso-Blanco C. Altitudinal and climatic adaptation is mediated by flowering traits and FRI, FLC, and PHYC genes in Arabidopsis. Plant Physiol. 2011;157:1942-55.

64. Caicedo AL, Stinchcombe JR, Olsen KM, Schmitt J, Purugganan MD. Epistatic interaction between Arabidopsis FRI and FLC flowering time genes generates a latitudinal cline in a life history trait. Proc Natl Acad Sci U S A. 2004:101:15670-5.

65. Kemi U, Niittyvuopio A, Toivainen T, Pasanen A, Quilot-Turion B, Holm K Lagercrantz U, Savolainen O, Kuittinen $\mathrm{H}$. Role of vernalization and of duplicated FLOWERING LOCUS C in the perennial Arabidopsis lyrata. New Phytol. 2013;197:323-35.

66. Nah G, Chen ZJ. Tandem duplication of the FLC locus and the origin of a new gene in Arabidopsis related species and their functional implications in allopolyploids. New Phytol. 2010;186:228-38.

67. Levy YY, Mesnage S, Mylne JS, Gendall AR, Dean C. Multiple roles of Arabidopsis VRN1 in vernalization and flowering time control. Science. 2002; 297:243-6.

68. Sherny ST, Ward MH, Kholodov M, Baker J, Phan L, Smigielski EM, Sirotkin K dbSNP: the NCBI database of genetic variation. Nucleic Acids Res. 2001;29:308-11.

69. Poduska B, Humphrey T, Redweik A, Grbic V. The synergistic activation of FLOWERING LOCUS C by FRIGIDA and a new flowering gene AERIAL ROSETTE 1 underlies a novel morphology in Arabidopsis. Genetics. 2003;163:1457-65.

70. Muhlhausen A, Lenser T, Mummenhoff K, Theißen G. Evidence that an evolutionary transition from dehiscent to indehiscent fruits in Lepidium, Brassicaceae; was caused by a change in the control of valve margin identity genes. Plant J. 2013;73:824-35.

71. Arnaud N, Lawrenson T, Ostergaard L, Sablowski R. The same regulatory point mutation changed seed-dispersal structures in evolution and domestication. Curr Biol. 2011;21:1215-9.

72. Konishi S, Izawa T, Lin SY, Ebana K, Fukuta Y, Sasaki T, Yano M. An SNP caused loss of seed shattering during rice domestication. Science. 2006:312:1392-6. 
73. Mummenhoff K, Polster A, Muhlhausen A, Theissen G. Lepidium as a model system for studying the evolution of fruit development in Brassicaceae. J Exp Bot. 2009;60:1503-13.

74. O'Neill CM, Gill S, Hobbs D, Morgan C, Bancroft I. Natural variation for seed oil composition in Arabidopsis thaliana. Phytochemistry. 2003;64:1077-90.

75. Ivarson E, Ahlman A, Lager I, Zhu LH. Significant increase of oleic acid level in the wild species Lepidium campestre through direct gene silencing. Plant Cell Rep. 2016;35:2055-63.

Ready to submit your research? Choose BMC and benefit from:

- fast, convenient online submission

- thorough peer review by experienced researchers in your field

- rapid publication on acceptance

- support for research data, including large and complex data types

- gold Open Access which fosters wider collaboration and increased citations

- maximum visibility for your research: over $100 \mathrm{M}$ website views per year 